\title{
An Overview of Inflammatory Bowel Disease: General Consideration and Genetic Screening Approach in Diagnosis of Early Onset Subsets
}

\author{
Shahram Nemati ${ }^{1}$, Shahram Teimourian ${ }^{2 *}$
}

1. Department of Medical Genetics, Tehran University of Medical Sciences,International Campus (TUMS-IC), Tehran, Iran.

2. Department of Medical Genetics, Iran University of Medical Sciences, Tehran, Iran

\footnotetext{
* Corresponding Author:

Shahram Teimourian Ph.D., P.D Department of Medical Genetics, Iran University of Medical Sciences. Tehran, Iran

Tel: +982186703243

fax: + 982188602209

Email: teimourian.sh@iums.ac.ir

Received: 14 Dec. 2016

Accepted: 02 Mar. 2017
}

\section{ABSTRACT}

Inflammatory bowel disease (IBD) is the consequence of an aberrant hemostasis of the immune cells at the gut mucosal border. Based on clinical manifestation, laboratory tests, radiological studies, endoscopic and histological features, this disease is divided into three main types including Crohn's disease (CD), Ulcerative colitis (UC), and IBDunclassified (IBD-U). IBD is frequently presented in adults, but about $20 \%$ of IBD cases are diagnosed during childhood called pediatric IBD (PIBD). Some patients in the latter group emerge the first symptoms during infancy or under 5 years of age named infantile and very early onset IBD (VEO-IBD), respectively. These subtypes make a small fraction of PIBD, but they have exclusive phenotypic and genetic characteristics such that they are accompanied by severe disease course and resistance to conventional therapy.

In this context, understanding the underlying molecular pathology opens a promising field for individualized and effective treatment. Here, we describe current hypotheses on IBD pathophysiology then explain the new idea about genetic screening technology as a good potential approach to identify the causal variants early in the disease manifestation, which is especially important for the fast and accurate treatment of VEO-IBD.

KEYWORDS:

Very early onset inflammatory bowel disease, Genetic screening approach, Next generation sequencing

Please cite this paper as:

Nemati S , Teimourian S. An Overview of Inflammatory Bowel Disease: General Consideration and Genetic Screening Approach in Diagnosis of Early Onset Subsets. Middle East J Dig Dis 2017;9:69-80. DOI: 10.15171/mejdd.2017.54.

\section{INTRODUCTION}

Although the exact mechanism of inflammatory bowel disease (IBD) is unknown, it is believed that an abnormal intestinal mucosal immune response to environmental triggers leads to an uncontrolled inflammation of epithelial cell lining of the intestine. ${ }^{1-3}$ The immune system of gut has a major role in providing an appropriate response to harmful pathogens; meanwhile, induces an immune tolerance to harmless food materials and commensal flora. ${ }^{4}$ This meticulous mechanism of immune hemostasis is disturbed in patients with IBD. Over the past several decades epidemiological studies have revealed an increase in the incidence and prevalence of IBD in adults and children. ${ }^{5}$ Reasons behind this is unclear, but alteration of lifestyle and nutritional habits are among prominent ones. ${ }^{6}$ Moreover, in some countries such as Iran, India, and China, along with industrialization and westernization, a growing number of these cases have been emerged. ${ }^{7}$

Needless to say, IBD is a complex disease and in contrast to common forms of these disorders in which an interaction among some genes and 
external factors leads to the disease, in a small subset of them a single gene can be held as an underlying factor inducing the disease. This latter group is called monogenic IBD, which is mostly manifested during infancy, but it has been reported, with a lesser extent, in later life ${ }^{8}$ With improvement of molecular technology like next generation sequencing (NGS) it is now proposed to screen whole exome/genome of candidate gene or genes to find out molecular pathology of the disease, and then we would be able to offer the best and evidence based treatment.

\section{PATHOGENESIS OF IBD}

\section{A-External Factors}

\section{1-Gastrointestinsl Microbiota}

A growing body of data indicates the importance of gut microbiom in the generation of immune hemostasis at gastrointestinal (GI) epithelial level. ${ }^{9-11}$ We can classify the gut luminal microorganisms into two major groups including beneficial microbes and pathogenic ones. GI tract is the natural habitat of a large number of microorganisms consisted of around 100 trillion microbes ${ }^{12}$ from more than 1000 species. ${ }^{13,14}$ This microbiota has a crucial role in the gut mucosa immune hemostasis. Any abnormalities in the interaction between the mucosal and the gut microbiom can lead to detrimental effect on the human health. At birth, the gut is largely free of any microorganism ${ }^{12}$ but during early few days of life the infants' gut initiates to be colonized by microorganisms of different groups. On conventional delivery, newborns get the primary GI flora from vaginal and fecal sources, while those who are delivered by caesarean section acquire their microbiota from hospital environment. ${ }^{15,16}$ it is believed that the first year of life is a vital time for establishing the gut microbiata by which making and maturation of the gut immune hemostasis ensue.

\section{2-Diet}

Much like microorganisms, diet has a crucial role in shaping the immune status of the gut. For instance, human milk in addition to providing nutritional requirements and immunity can be a source of beneficial bacteria. ${ }^{17}$ Moreover, in vitro experiments have documented that some ingredients of milk such as human milk oligosaccharides (HMOS) are beneficial to the health of the gut. ${ }^{18}$ Cruciferous vegetables are other striking examples, which show the role of diet in controlling the immune activity. It has been documented that some chemical compounds of these substances can bind to aryl hydrocarbon receptors (AhRs). These receptors are abundant in intraepithelial lymphocytes (IELs), which are mainly CD8 positive T cells. And binding of AhRs with their ligands leads to activation of Treg (The regulatory T- cells) inducing and maintaining tolerance.$^{19-21}$

\section{B- Internal factors}

\section{1- The architecture of gut lining cells}

In addition to nutrient absorption, epithelial lining cells have some specialized and differentiated cell lineages such as goblet, Paneth, and microfold (M) cells isolating milieu beneath the epithelial sheets from luminal contents and concurrently orchestrate the immune hemostasis along the gut mucosa. Any abnormalities in the architecture and biology of lining cells can cause inflammation. ${ }^{1,22}$

These epithelial cell sheets function as a barrier against exposure of luminal content to the circulation. This ability depends on stability of tight junctions, which act like seals between cells. ${ }^{22}$ Goblet cells, interspersed within epithelial cells, produce mucin layer covering the gut cell sheets by which they make a protection against invasion of pathogens, toxin, enzymes, and abrasion. It is noteworthy to notice that mucus structure is different in small and large intestine. In contrast to a single layer in small intestine, there is a dual structure in colon. The latter has been made from two separate layers, the inner part is denser than the outer layer, and thereby it limits microbes' attachment to epithelial lining cells especially in colon with a larger community of microorganisms. Additionally, these dual layers prevent from flaring of inflammatory response to commensal flora of the colon. ${ }^{23}$ It can be hypothesized that this special structure of mucin in colonic part of the intestine makes limitation in motility and adherence of commensal or pathogen microorganisms to the gut lining cells. Therefore, it is not surprising any mutation causing disruption in normal function of mucin producing cells (Goblet cells) re- 
sults in an inflammatory response. Regarding this, it is documented that deletion of Muc2 (mucin) gene in mice causes spontaneous colitis. ${ }^{24}$

The second type of the gut lining cells is the Paneth cells located at the bottom of intestinal crypts. They have major role in controlling the microbial population and the mucosal immune hemostasis. Paneth cells secrete some vital effectors including lysozyme and phospholipase A2, defensins HD5, and HD6 inducing microbial cell lysis. These substances are produced in response to exogenous triggers like bacterial components such as lipopolysaccharide (LPS), lipoteichoic acid (LTA), and Muramyle dipeptide (MDP). Secretion of these antimicrobial peptides (AMPS) are mediated by Toll-like receptors (TLRS) and NOD2 signaling pathways. ${ }^{1,25}$

It is clear that any disturbance to the biological pathways of intestinal epithelial cells (IELs), implicated in the maintenance of integrity and functionality, leads to pathological impact. For instance, genes that control barrier integrity (CDH1, GNA12, PTP2) ${ }^{26-28}$, epithelial regeneration (HNF4 and NKX2-3) $)^{29,30}$ and those destabilize the tight junction through activation of $\mathrm{G}$ protein (encoded by GNA12 ) or non-functional connexin-43 31 all could increase the risk of intestinal disorders.

Intraepithelial lymphocytes (IELs) are among the gut lining cells, which are subdivided by their specific surface TCR(T-cell receptor) into $\gamma \delta$ and $\alpha \beta$ T cells. In mice, it has been shown that gamma delta ones are preferably organized at the epithelial layer of skin, uterus, and intestine. ${ }^{32}$ The $\gamma \delta \mathrm{T}$ cells have cytolytic and cytoprotective activities such that they secrete antibacterial lectin, Reg $\amalg \gamma$, or emerge killer activities in response to the infection of enterocytes. ${ }^{33}$ It has also been shown that gammadelta IELs are important in suppressing inflammation in the gut. ${ }^{34}$

In order to establish the mucosal immune hemostasis, the gut epithelium must be able to introduce the luminal content to the immune system lying beneath the epithelial sheets. This process is very critical in the determination of immune fate; tolerance against activation. There are some special and different cells committed to do this named antigen presenting cells (APC) classified under two main groups.

Enterocytes pass luminal contents by receptor- mediated pinocytosis. Firstly, exogenous materials are engulfed and through passing across the cell they processed and expressed on the opposite side of the cell-basolateral side- in close proximity to major histocompatibility complex (MHC). It is intriguing that under normal conditions, the gut substances are expressed without co-stimulatory molecules such as B7-1 or B7-2 and presentation of this kind induce anergy of CD4+ T-cells to specific antigen. ${ }^{35}$ The dendritic cells (DCs) are the second type of APCs. These cells are different in terms of markers they express and places they locate. They have been scattered throughout the intestine including lamina propria, which is the home to CD 103+ and CD 103- DCs and Peyers patches encompassing CD $103+$ cells. It has been shown that CD 103+ DCs have an important role in tolerogenic response. ${ }^{36}$ The DCs that are CX $3 \mathrm{CR} 1+$ connect to the gut lumen by an extended arm-liked project that pass from tight junction between cells by which they can taste the lumen content. On the other hand, It has been documented that antigen transferring between cells is a connexin 43-dependent manner and any fault in this pathway prevents CD103+ DCs from presenting antigen to $\mathrm{T}$ regulatory cells and subsequently tolerogenic response would not be ensued..$^{31}$ Additionally, the GI tract is filled with lymphoid structure, so it is not surprising any abnormalities in both arms of the immune system could affect the normal function of the gut. Chronic granulomatosis disease (CGD) is an obvious example of innate-mediated immunodeficiency in which disturbance in nicotinamide adenine dinucleotide phosphate (NADPH) oxidase complex is linked to IBD-like complication. ${ }^{37-39}$ The immune system of these patients is not able to eradicate foreign microorganisms and eventually results in inflammation and granuloma formation.

\section{2-The genetics factors}

Epidemiological evidence, ethnic tendency, and family and twin studies all reveal that genetic components play an important role in IBD. It has been shown that different ethnicity/racial groups have different prevalence. This disease is more common 
in white and has high prevalence in North America, Northern Europe, and UK. ${ }^{40,41}$ In addition, the rate of disease is higher among people of Jewish population 42 especially Ashkenazi Jews. Moreover, familial aggregation studies of the IBD with different types, CD or UC, and also twin studies show a high concordance in monozygotic twins compared with fraternal ones. Additionally, the relative sib risk, $\lambda s$, is $30-40$ for CD and 10-20 for UC. ${ }^{43,44}$ Concordance of IBD among monozygotic twins together with the aggregation of the disease in families are in favor of the genetic role in the disease pathogenesis. On the other hand, occurring IBD in immigrants to countries with the high prevalence of the disease along with an increasing number of the disease with industrialization and westernization in area with previously low rate prevalence such as Iran, India, Lebanon, and South Korea, ${ }^{45}$ all highlight the significant effect of environmental triggers in the IBD.

Regarding this, a large growing body of evidence suggests that genetic susceptible genes and interaction of them with environmental factors are critical in the disease pathogenesis. Over the past decades, international researchers have been collaborated to search for IBD susceptibility factors. At first, they used informative microsatellite markers to find susceptibility locus based on linkage analysis strategies. But, this type of study has some drawbacks in mapping genes conferring susceptibility to the complex diseases. This low success rate of linkage analysis to identify causative genes was the reason why in 1996 Rish and Merikangas declared association studies were more powerful tools for detection of the disease underlying genes. The best marker for this purpose is single nucleotide polymorphisms (SNPs) because they are abundant across the human genome and in comparison with microsatellite the probability of mutation occurrence is low; additionally, genotyping of them is easy. Novel technologies provide an opportunity to scan throughout the genome for finding susceptibility loci. Genome wide association studies (GWAS) have detected many loci as the causal factors. Identification of these variants shed light on the pathways involved in the IBD pathogenesis. ${ }^{46}$ With better understand- ing of molecular pathology of the disease, the better treatment ensues. Recent GWAS have identified 163 loci for IBD, some of which are common in other inflammatory diseases. ${ }^{47}$ More recently, it has been documented that of the 163 loci, 30 loci are specific to CD, 23 loci to UC, and 110 loci are in common. ${ }^{48}$ Additionally, an analysis comprising individuals of European and non-European countries have detected 38 new additional loci. ${ }^{49}$

Obviously, GWAS have unprecedented ability to find susceptibility factors that play an important role in the pathogenesis of the disease and confer a relative risk to carrier of them. But, it must be taken into consideration that association instead of being a genetic event is a statistical statement. Most association studies seek to find linkage disequilibrium (LD), which means by using biomarkers such as tag-SNPs it could identify a haplotype block that is linked to the disease susceptibility factors. It is also important to note association studies do genotyping a large number of tagging SNPs determined by Hap Map project. These variants lie on the ancient hyplotype blocks and persist during thousands of generations of natural selection. So, they have very mildly detrimental effects and high frequency in populations. In addition, common diseases have a spectrum of genetic determinations. At one end, there are variants with very small influence and at the other end there are variants with a major effect that cause Mendelian subsets. Somewhere between these extremities there are variants with a modest power that are strong enough to undergo natural selection and finally, to be removed from human genome. The process is balanced by de novo mutation that inserts new variants into genome. The fact that GWAS are the means to identify ancient common variants that persisted through many generations of natural selection, tells us for variants with rapid turnover such as Mendelian and those with a modest power, which we described above, will not be appropriate methods. Instead, we need to do resequencing of candidate genes, whole genome, or exome to pick up recent or new mutations.

\section{IBD CLASSIFICATIONS}


IBD is a heterogeneous disease with a wide range of phenotypic manifestations. The classification of IBD in such a way that covers all phenotypes is difficult because there are some rare phenotypes with distinct and unconventional properties. However, it is mainly divided into two types including Crohn's disease (CD) and ulcerative colitis (UC). Sometimes patients who reveal colonic involvement without typical finding for $\mathrm{CD}$ or UC are classified as UIBD. ${ }^{50}$ But, this stratification could not include all phenotypes in appropriate groups. Subclassification of IBD was revised in Vienna, in 1988, and some variables including the age of onset, behavior, and location of disease were added. ${ }^{51}$ In the second revision, the Montreal classification, the number of variables was not modified, but some changes within each parameter were created. ${ }^{52}$ The patient with IBD in whom the disease manifests under 17 years of age are considered as having pediatric IBD (PIBD), which is about $20-25 \%$ of IBD. The Montreal classification had weaknesses in categorization of PIBD until the pediatric Paris classification defined PIBD as A1 group and then further divided that into A1a for those with the onset under 10 years of age and A $1 \mathrm{~b}$ when the disease manifests initially between 10 and 17 years of age. Some papers describe the A1a group as early onset IBD and the disease that is presented under 6 years of age is named as very early onset IBD (VEO-IBD) constituting $15 \%$ of PIBD. ${ }^{53}$ Finally a small group of patients with PIBD (less than $1 \%$ ) fall into infantile IBD group who have the disease during the first year of life.

PIBD and adult IBD have clear difference in their genetic background and the course of the disease. ${ }^{54}$ Some studies have suggested that childhood onset IBD has extended involvement of GI tract and different response to therapy. ${ }^{55}$

\section{Epidemiology of IBD}

The prevalence of adult IBD is higher in Europe with predominance of UC over CD (505 and 322 per 100000 per year, respectively). Interestingly, increasing numbers of the disease have been reported in some areas with previously low prevalence. ${ }^{56}$ Many studies before 1990s revealed that the incidence of
Table 1: Important pathways involved in VEO-IBD pathogenesis

\begin{tabular}{l}
\hline 1- G-protein coupled receptors \\
\hline 2- Innate and adaptive immunity \\
\hline 3- The pathways linked to the epithelial lining cell biology \\
\hline 4- Th17 pathway \\
\hline 5- T-cell negative regulator including: \\
\hline -IL-10 signaling pathway \\
\hline -T reg cells activity \\
\hline
\end{tabular}

the PIBD was increasing with the predominance of $\mathrm{CD}$ over UC. ${ }^{57} \mathrm{But}$, this increasing trend in the number of disease is limited to a specific age. Regarding to these studies, increasing in the incidence rate of PIBD is evident among children older than 10 years. On the contrary, this is not true in children under 5 years of age. As a whole, such evidence suggests that genetics are stronger factors in VEO-IBD and infantile IBD compared with environmental elements that are crucial in the conventional IBD..$^{58}$

Therefore, a special consideration should be taken into account for genetic aspect of the PIBD. As aforementioned, GWAS have revealed a lot of loci involving in the pathogenesis of the disease. Most of them are implicated in seven distinct pathways (table 1)..$^{59,60 .}$

\section{DIAGNOSIS}

Generally, the diagnosis of IBD is established based on clinical presentation, physical examination, endoscopic/histological findings, and imaging studies. According to Porto criteria prepared in March 2004 in Portugal, any child with symptoms such as abdominal pain, diarrhea, weight loss, and rectal bleeding with continuous ( $\geq 4$ weeks) and relapsing manner ( $\geq 2$ episodes in 6 months) should be considered as probably having the disease. Despite similarities in adult onset IBD and PIBD, some unique features are emerged by the latter type. Of these, we can point out to delay in growth and puberty and impairment of skeletal development. ${ }^{61,62}$ In fact, $85 \%$ of PIBD with $\mathrm{CD}$ and $65 \%$ of patients with UC have growth failure as a major symptom at the time of visiting. ${ }^{62,63}$ Severe psychological disorders, risk of cancers, and surgical interventions are among other concerns that 
Table 2: Key Findings in IBD subsets

\begin{tabular}{lcc}
\hline \multicolumn{1}{c}{$\begin{array}{c}\text { Contributing triggers and disease } \\
\text { features }\end{array}$} & \multicolumn{2}{c}{ Types of disease } \\
\cline { 2 - 3 } & Conventional IBD & Monogenic IBD \\
\hline Environmental factors & stronger & weaker \\
\hline Genetic background & Complex & Mendelian \\
\hline Frequency of subtypes & UC & CD \\
\hline The course of disease & Milder & Severe \\
\hline Response to therapy & Good & Poor \\
\hline Atypical finding in endoscopy and histology & Lesser & More \\
\hline Age of onset & $>7$ Yrs & $<6$ Yrs \\
\hline Perianal disease & Lesser & More \\
\hline Consanguinity & Important & Essential \\
\hline Sexuality & A subtle difference & A male predominance \\
\hline
\end{tabular}

should be considered. Owing to a large burden of delay in the diagnosis of the PIBD, early and accurate non-invasive techniques for screening the underlying causes of the disease, and then definitive diagnosis is essential for the targeted and effective treatment. The mean delay in the diagnosis of the PIBD with CD and UC phenotypes are 1-11 months and 5-8 months, respectively. ${ }^{62}$ Full endoscopic investigation is a gold standard for the diagnosis of the PIBD. ${ }^{64}$ According to revised Porto criteria, Ileocolonoscopy and esophagogastroduodenoscopy (EGD) are recommended at the initial diagnostic evaluation. Small bowel imaging is recommended in all cases with IBD, especially those with IBD-U. ${ }^{65}$ It has been documented that under 6 years of age, there is a notable increase in monogenic form of IBD. On the other hand, after the age of 7 years, the frequency of conventional polygenic IBD increases. ${ }^{66,67}$ Moreover, around one-fifth of PIBD younger than 6 years and one-third of those before 3 years of age are diagnosed as IBD-U. ${ }^{68}$ This latter group includes patients with definite IBD in whom the inflammation is confined to colon, but differentiation between UC and $\mathrm{CD}$ even after a complete diagnostic evaluation is not obtainable. ${ }^{65}$ In addition, there is a broad spectrum of rare genetic disorders that are monogenic and mimic IBD manifestations. Diagnosis of them provide an evidence-based therapy by which complete cure would not be far from access. Moreover, rapid and definitive diagnosis helps us to save time and prevent from using inappropriate treatment that is very important in the effectiveness of treatment. Current diagnostic guidelines cannot represent a complete approach in the differential diagnosis of all these orphan diseases.

These findings have addressed the need for a much more detailed classification and using a novel and suitable diagnostic approach to identify the underlying causes of these special subsets. Genetic screening makes an opportunity to achieve a considerable success in the diagnosis of the molecular pathology of the disease. Regarding this, GWAS is suitable method for identifying variants that are common in population and likely present on shared ancient blocks, which have very small individual effects on the disease susceptibility. Instead, when we deal with rare variants with stronger individual effects that likely to be produced by recent mutation, it would be necessary to screen candidate gene or genes of interest to pick up the postulated variants.

Accurate diagnosis is the mainstay of effective treatment. For this, we need a complete and knowledge-based diagnostic evaluation by which we can improve the chance of the definitive diagnosis. In addition, considering some cues in the context of GI symptoms, such as the age of onset, extraintestinal manifestations such as perianal disease, the inheritance pattern of the disease, consanguinity, treatment failure with conventional medications, familial aggregation, and specific clinical findings, guide us to think about the possibility of specific causal elements (table 2). ${ }^{66,69}$ 


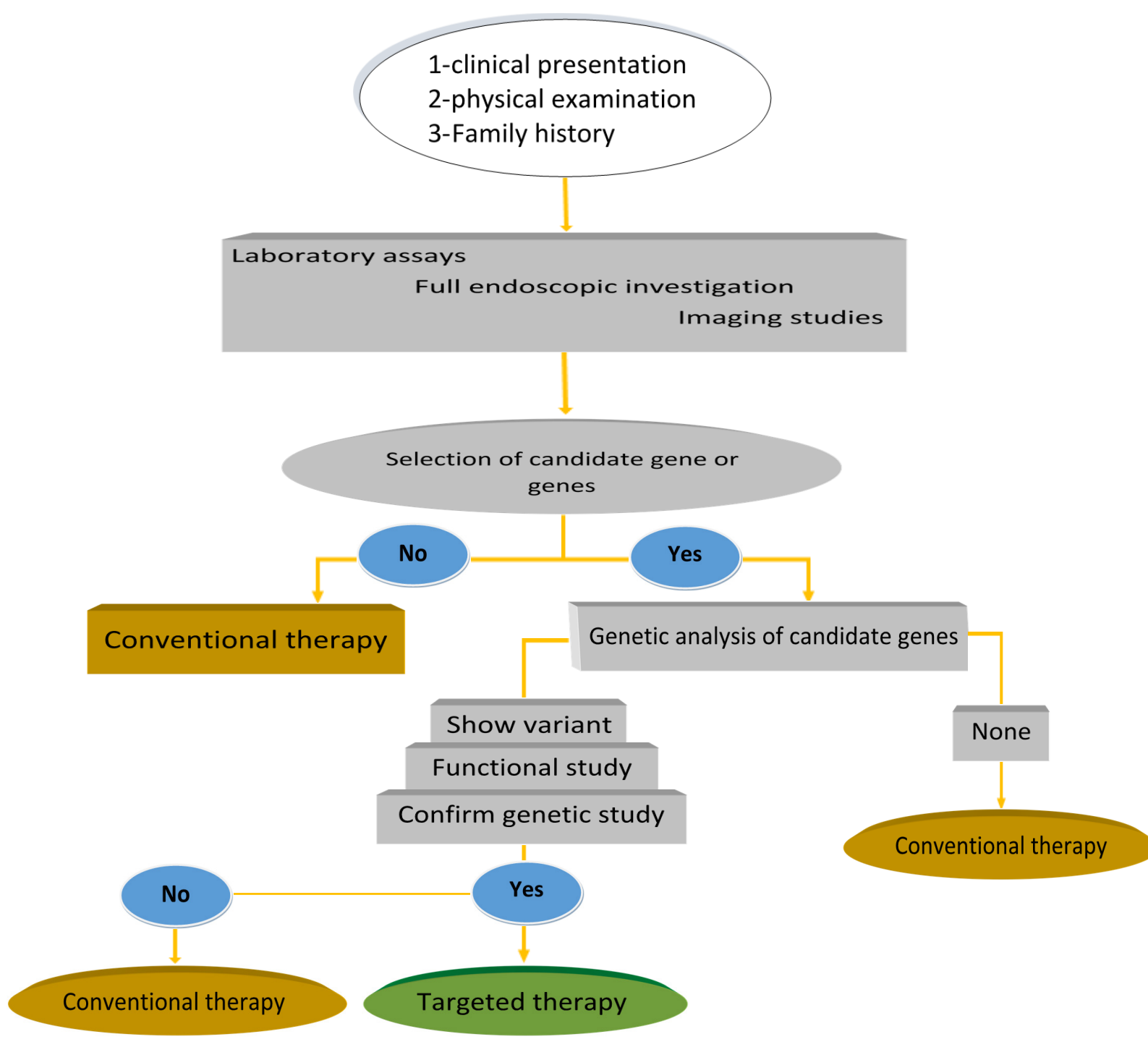

Fig.1: The current strategies for PIBD. It is important to rule out enteric infection. For monogenic IBD the data obtained by preliminary measures are used as a guidance to define the candidate genes, which must be screened to find out the underlying causal variants.

\section{Diagnostic Approach to PIBD}

Lack of a precise method for phenotyping of the PIBD leads to categorization of some subtypes within U-IBD. So, it is important to use novel strategies to recognize the underlying molecular pathology of the disease without delay. In the current classic strategies, initial functional studies are followed by genetic testing. As it is mentioned before, there are many rare genetic diseases with GI manifestations that distinguishing them from each other, solely based on current diagnostic evaluation, is frequent- ly known as a challenge. In the classic strategies, the diagnostic approach for PIBD begins by physical examination, taking of medical, clinical, and family history followed by other complementary assays. If there is an index of suspicion about some genetic variants, as the underlying causes, genetic screening is done. But, it is time-consuming and costly and in most cases it does not lead to a definitive diagnosis (figure 1). By this approach, it is only possible to divide the disease into $\mathrm{CD}, \mathrm{UC}, \mathrm{U}-\mathrm{IBD}$, and IBD-like disorders. Therefore, for subtyping 


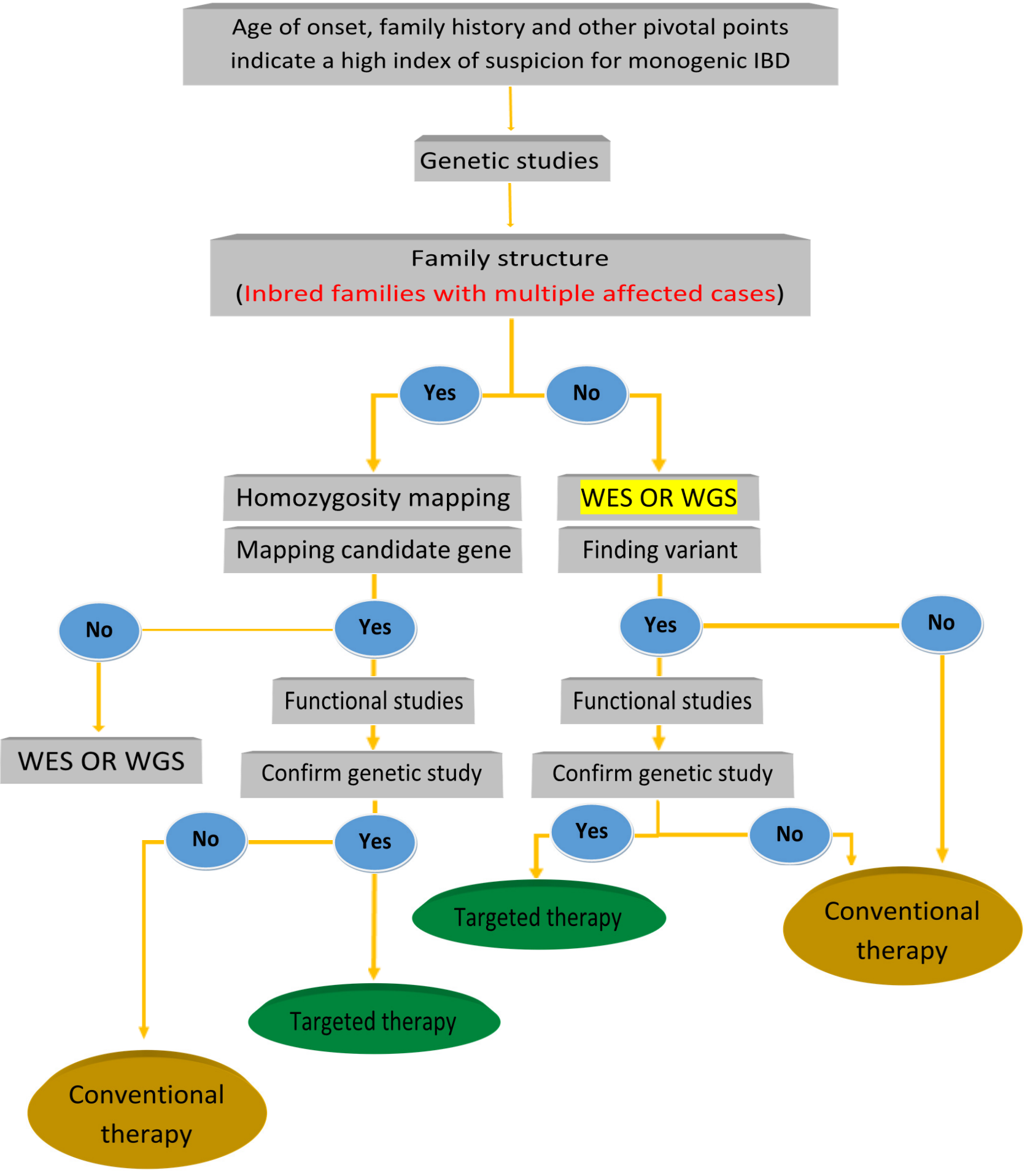

Fig.2: The supposed strategy to approach patients was suspected monogenic IBD. The importance of early and precise diagnosis in the outcome of the disease convinces researchers using parallel genetic screening followed by functional studies in the initial steps as an alternative option for making a diagnosis with higher sensitivity. In this context the early and targeted therapy would not be far from access. 
and distinguishing monogenic types from the conventional polygenic ones, we need a more powerful tool to deal with this problem. Moreover, by using some specific phenotypic characteristics we can make a good degree of suspicion for the underlying factors of the disease. For instance, finding trichorrhexis nodosa, which is an abnormality in the hair shaft, in the context of abdominal discomfort creates a strong suspicion toward a genetic defect in tetratricopeptide repeat domain 37 (TTC37) gene as an underlying cause of monogenic IBD. Additionally, age is one of the most important elements in discrimination of IBD subtypes, which means the beginning of IBD before 2 years of age is in favor of monogenic type of the disease. Some genetic variants are exclusively identified in the certain timescale. For example, IL-10 signaling pathway defect is reported just in infancy or early childhood, while both Wiskott-Aldrich (WAS) and Immune Dysregulation, Polyendocrinopathy, Enteropathy, X-Linked (IPEX ) are described early and late in life. ${ }^{70,71}$

By improving sequencing technologies, we are able to identify the sequences of large amount of genome in parallel at a greatly reduced cost over a very short time. Adding reliability and precision features to these novel sequencing methods makes them powerful and special means by which human genome studies have been revolutionized. ${ }^{72}$ In this context, it is not surprising to be faced with some modifications in classic approach for better diagnosis of the underlying causal factors of the PIBD. Based on this modified approach at first the whole genome/exome WES(whole exome sequencing) or WGS (whole genome sequencing) of candidate genes are monitored by NGS method. When potential variants are identified their biological effects must be confirmed by additional functional studies (figure 2).

\section{CONCLUSION:}

In current practice, the starting point to deal with IBD is the analysis of the clinical findings and performing a combination of physical examinations, laboratory, and diagnostic evaluations. This approach is not a good strategy in differentiation between monogenic and conventional IBD, which are discrete entities and need different approaching in terms of diagnosis and treatment. In the NGS era it is now possible to modify the starting point to increase the likelihood of accurate and rapid diagnosis that is necessary to ensure effective treatment. In this new strategy, early genomic screening is used in an effort to find causative genetic variants then followed by functional studies. In this way, we will be able to find out some variants with complete and incomplete penetrance with variable effect on gene function. This facilitates to define genotypephenotype correlation and recognize subsets that have already been categorized as U-IBD. On the other hand, with improving our knowledge in cell biology and signaling pathways contributing to the gut hemostasis, it would be a lot easier to detect the underlying cause of the IBD by targeted screening of genes of interest. More recently, it has been proposed that miRNA and epigenetic mechanism may play a notable role in the IBD pathogenesis. ${ }^{48}$ The identification of normal gene expression profile at either transcript or protein level across the gut lining cells, will provide a comprehensive description of cells activity over entirely distinct part of the gut. In this context, it could be postulated that during histology examination by comparing the gene expression profile in health and disease status, in the future it might be feasible using these features as biomarkers to make a preliminary diagnosis in both of the monogenic and even conventional polygenic IBD directing therapeutic strategies.

\section{CONFLICT OF INTEREST}

The authors declare no conflict of interest related to this work.

\section{REFERENCES}

1. Khor B, Gardet A, Xavier RJ. Genetics and pathogenesis of inflammatory bowel disease. Nature 2011;474:307317. doi:10.1038/nature 10209

2. Belkaid Y, Hand TW.Role of the microbiota in immunity and inflammation. Cell 2014;157:121-41. doi: 10.1016/j. cell.2014.03.011

3. Abraham C, Cho JH. Inflammatory bowel disease. $N$ Engl $J$ Med 2009;361:2066-78. doi: 10.1056/NEJMra0804647 
4. Cader MZ, Kaser A. Recent advances in inflammatory bowel disease: mucosal immune cells in intestinal inflammation. Gut 2013;62:1653-64. doi:10.1136/ gutjnl-2012-303955.

5. Burisch, Johan; Munkholm, Pia.Inflammatory bowel disease epidemiology . Curr Opin in Gastroenterol 2013;29:357-62. doi:10.1097/MOG.0b013e32836229fb.

6. Gent AE, Hellier MD, Grace RH, Swarbrick ET, Coggon D. Inflammatory bowel disease and domestic hygiene in infancy. Lancet 1994;343:766-7. doi: 10.1016/S01406736(94)91841-4.

7. Ng SC, Bernstein CN, Vatn MH, Lakatos PL, Loftus EV $\mathrm{Jr}$, Tysk C, et al. Geographical variability and environmental risk factors in inflammatory bowel disease. Gut 2013;62:630-49. doi:10.1136/gutjnl-2012-303661.

8. Uhlig HH, Schwerd T, Koletzko S, Shah N, Kammermeier J, Elkadri A, et al. The diagnostic approach to monogenic very early onset inflammatory bowel disease. Gastroenterology 2014;147:990-1007 e1003. doi: 10.1053/j. gastro.2014.07.023

9. Otte JM, Podolsky DK. Functional modulation of enterocytes by gram-positive and gram-negative microorganisms. Am J Physiol Gastrointest Liver Physiol 2004; 286:613-626. doi: 10.1152/ajpgi.00341.2003.

10. Evrard B, Dosgilbert A, Charbonnel N, Alamé J, Tridon A, Forestier C, et al. Dose-dependent immunomodulation of human dendritic cells by the probiotic Lactobacillus rhamnosus Lcr35. PLoS One 2011;6:e18735. doi:10.1371/ journal.pone.0018735.

11. Junjie Qin, Ruiqiang Li,1, Jeroen Raes. A human gut microbial gene catalog established by metagenomic sequencing. Nature 2010;464:59-65.doi: 10.1038/nature08821.

12. Ley RE, Peterson DA, Gordon JI. Ecological and evolutionary forces shapingmicrobial diversity in the human intestine. Cell 2006;124 :837-48. doi: 10.1016/j. cell.2006.02.017.

13. Gill SR, Pop M, Deboy RT, Eckburg PB, Turnbaugh PJ, Samuel BS,et al. Metagenomic analysis of the human distal gut microbiome. Science 2006;312:1355-9. doi: 10.1126/science. 1124234 .

14. Turnbaugh PJ, Yatsunenko T, Cantarel BL, Duncan A, Ley RE, Sogin ML, et al. A core gut microbiome in obese and lean twins. Nature 2009;457:480-4. doi:10.1038/nature 07540 .

15. Penders J, Vink C, Stelma FF, Snijders B, Kummeling I, van den Brandt PA, et al. Factors influencing the composition of the intestinal microbiota in early infancy. Pediatrics 2006;118:511-21.

16. Biasucci G, Benenati B, Morelli L, Bessi E, Boehm G. Cesarean delivery may affect the early biodiversity of intestinal bacteria. J Nutr 2008;138:1796S-1800S.

17. Albesharat R, Ehrmann MA, Korakli M, Yazaji S, Vogel RF. Phenotypic and genotypic analyses of lactic acid bacteria in local fermented food, breast milk and faeces of mothers and their babies. Syst Appl Microbiol
2011;34:148-55. doi:10.1016/j.syapm.2010.12.001

18. Yu ZT, Kling DE, Liu B, McCoy JM, Merighi M, Heidtman M, et al.The principal fucosylated oligosaccharides of human milk exhibit prebiotic properties on cultured infant microbiota. Glycobiology 2013;23:169-77. doi:10.1093/ glycob/cws 138 .

19. Kiss EA, Vonarbourg C, Kopfmann S, Hobeika E, Finke D, Esser C,et al. Natural aryl hydrocarbon receptor ligands control organogenesis of intestinal lymphoid follicles. Science 2011;334:1561-5. doi: 10.1126/science.1214914.

20. Li Y, Withers DR, Roberts NA, Gallagher AR, Grigorieva EF, Wilhelm C, et al. Exogenous stimuli maintain intraepithelial lymphocytes via aryl hydrocarbon receptor activation. Cell 2011;147:629-40. doi: 10.1016/j. cell.2011.09.025.

21. Schulz VJ, Willemsen KJ, Fiechter D, Hassing I, Bleumink R, Boon L, et al. Activation of the aryl hydrocarbon receptor suppresses sensitization in a mouse peanut allergy model. Toxicol Sci 2011;123:491-500. doi:10.1093/ toxsci/kfr 175 .

22. Turner JR. Molecular basis of epithelialbarrier regulation: from basic mechanismsto clinical application. Am J Pathol 2006;169;:1901-1909. doi: 10.2353/ajpath.2006.060681.

23. Johansson ME, Hansson GC. The two mucus layers of colon are organized by the MUC2 mucin, whereas the outer layer is a legislator of host-microbial interactions. Proc Natl Acad Sci U S A 2011;15(108 Suppl 1):4659-65. doi: 10.1073/pnas. 1006451107 .

24. Van der Sluis M, De Koning BA, De Bruijn AC, Velcich A, Meijerink JP, Van Goudoever JB, et al. Muc2-deficient mice spontaneously develop colitis, indicating that MUC2 is critical for colonic protection. Gastroenterology 2006;131:117-29. doi: 10.1053/j.gastro.2006.04.020

25. Ayabe T, Pesendorfer P, Tanabe H, Wilson CL, Hagen SJ, Ouellette AJ. Activation of Paneth cell alpha-defensins in mouse small intestine. J Biol Chem 2002;277:5219-28.

26. Muise AM, Glowacka WK, Griffiths AM, Ngan BY, Lan H, Xu W, Silverberg MS, et al. Polymorphisms in E-cadherin (CDH1) result in a mis-localised cytoplasmic protein that is associated with Crohn's disease. Gut 2009;58:1121-7. doi:10.1136/gut.2008.175117.

27. Sabath E, Beaudry S, Paniagua M, Angelow S, Shah J, Grammatikakis N, et al. Galpha12 regulates protein interactions within the MDCK cell tight junction and inhibits tight-junction assembly. J Cell Sci 2008;121:814-24. doi 10.1242/jcs.014878.

28. Scharl M, Weber A, Jung BC, Docherty MJ, Hausmann M, Rogler G, et al. Protection of epithelial barrier function by the Crohn's disease associated gene protein tyrosine phosphatase N2. Gastroenterology 2009;137:2030-40. doi: 10.1053/j.gastro.2009.07.078.

29. Darsigny M, Babeu JP, Dupuis AA, Furth EE, Seidman EG, Lévy E, et al. Loss of Hepatocyte-Nuclear-Factor$4 \alpha$ Affects Colonic Ion Transport and Causes Chronic Inflammation Resembling Inflammatory Bowel Disease 
in Mice. PLoS One 2009;4: e7609. doi:10.1371/journal. pone. 0007609 .

30. Pabst O, Zweigerdt R, Arnold HH. Targeted disruption of the homeobox transcription factor Nkx2-3 in mice results in postnatal lethality and abnormal development of small intestine and spleen. Development 1999;126:2215-25.

31. Mazzini E, Massimiliano L, Penna G, Rescigno M. Oral tolerance can be established via gap junction transfer of fed antigens from $\mathrm{CX} 3 \mathrm{CR} 1^{+}$macrophages to $\mathrm{CD} 103^{+}$ dendritic cells. Immunity 2014;40:248-61. doi: 10.1016/j. immuni.2013.12.012.

32. Itohara S, Lafaille JJ, Bonneville M, Takagaki Y, Haas W, Tonegawa S. Homing of a gamma delta thymocyte subset with homogeneous T-cell receptors to mucosal epithelia. Nature 1990;343:754-7. doi:10.1038/343754a0.

33. Ismail AS, Vaishnava S, Behrendt CL, Yu X, Benjamin JL, Ruhn KA, et al. Gammadelta intraepithelial lymphocytes are essential mediators of host-microbial homeostasis at the intestinal mucosal surface. Proc Natl Acad Sci U S A 2011;108:8743-8. doi: 10.1073/pnas.1019574108.

34. Roselli M, Finamore A, Nuccitelli S, Carnevali P, Brigidi $\mathrm{P}$, Vitali $\mathrm{B}$,et al. Prevention of TNBS-induced colitis by different Lactobacillus and Bifidobacterium strains is associated with an expansion of $\gamma \delta \mathrm{T}$ and regulatory $\mathrm{T}$ cells of intestinal intraepithelial lymphocytes. Inflammatory Bowel Diseases 2009;15:1526-36. doi: 10.1002/ ibd.20961.

35. Bloom S. Simmons D, Jewell DP. Adhesion molecules intercellular adhesion mole-1 (ICAM-1), ICAM-3 and B7 are not expressed by epithelium in normal or inflamed colon. Clin Exp Immunol 1995;101:157-63. doi: 10.1111/ j.1365-2249.1995.tb02292.x.

36. Ruane DT, Lavelle EC. The Role of CD103+ Dendritic Cells in the Intestinal Mucosal Immune System. Front Immunol 2011, doi:10.3389/fimmu.2011.00025.

37. Teimourian S, de Boer M, Roos D. Molecular basis of autosomal recessive chronic granulomatous disease in Iran. $J$ Clin Immunol 2010;30:587-92. doi: 10.1007/s10875010-9421-6.

38. Teimourian S, Badalzadeh M, Pouya A, Kannengiesser C, Mansouri D, Cheraghi T, et al. Characterization of six novel mutations in CYBA: the gene causing autosomal recessive chronic granulomatous disease. Br J Haematol 2008;141:848-51. doi: 10.1111/j.13652141.2008.07148.x.

39. Teimourian S, Badalzadeh M, Kannengiesser C, Mansouri D, Movahedi M, Zomorodian E, et al. Molecular diagnosis of $\mathrm{X}$-linked chronic granulomatous $\mathrm{d}$ isease in Iran. Int J Hematol 2008;87:398-404. doi: 10.1007/ s12185-008-0060-0.

40. Loftus EV Jr . Clinical epidemiology of inflammatory bowel disease: Incidence, prevalence, and environmental influences. Gastroenterology 2004;126:1504-17. doi: 10.1053/j.gastro.2004.01.063.PMID:15168363.

41. Bernstein CN, Blanchard JF, Rawsthorne P, Wajda A. Epi- demiology of Crohn's disease and ulcerative colitis in a central Canadian province: a population-based study. $\mathrm{Am}$ J Epidemiol 1999;149:916-24. doi:10.1093/oxfordjournals.aje.a009735.

42. Sandler RS TS, Shanahan F. Epidemiology Inflammatory Bowel Disease: from bench to bedside.: Baltimore MD: Williams \& Wilkins,; 1994:5-30.

43. Satsangi J, Jewell DP, Bell JI. The genetics of inflammatory bowel disease. Gut 1997;40:572-4. PMC1027155.

44. Cho JH. Inflammatory bowel disease: Genetic and epidemiologic considerations. World $J$ Gastroentero 2008;14:338-47.

45. Ng SC, Vatn MH, Lakatos PL, Loftus EV Jr, Tysk C, O'Morain C, et al.Epidemiology and Natural History Task Force of the International Organization of Inflammatory Bowel Disease (IOIBD). Geographical variability and environmental risk factors in inflammatory bowel disease. Gut 2013;62:630-649. doi:10.1136/gutjnl-2012-303661.

46. Baumgart DC. Crohn's disease. Lancet 2012;380:15901605. doi: 10.1016/S0140-6736(12)60026-9.

47. Jostins L RS, Weersma RK, Duerr RH, McGovern DP, Hui $\mathrm{KY}$, Lee JC, et al. Host-microbe interactions have shaped the genetic architecture of inflammatory bowel disease. Nature 2012;491:119-24. doi:10.1038/nature11582.

48. Loddo I, Romano C. Inflammatory Bowel Disease: Genetics, Epigenetics, and Pathogenesis. Front Immunol 2015;6:551. doi:10.3389/fimmu.2015.00551.

49. Liu JZ, van Sommeren S, Huang H, Ng SC, Alberts R, Takahashi A, et al.: Association analyses identify 38 susceptibility loci for inflammatory bowel disease and highlight shared genetic risk across populations. Nature Genetics 2015;47:979-86. doi:10.1038/ng.3359.

50. Gasche C, Brynskov J, D'Haens G, Hanauer SB, Irvine EJ, Jewell DP, et al. A simple classification of Crohn's disease: report of the Working Party for the World Congresses of Gastroenterology, Vienna 1998. Inflamm Bowel Dis 2000;6:8-15. doi: 10.1002/ibd.3780060103.

51. Rigoli L, Caruso RA. Inflammatory bowel disease in pediatric and adolescent patients: A biomolecular and histopathological review. World J Gastroenterol 2014; 20:10262-78. doi: 10.3748/WJG.v20.i30.10262.

52. Silverberg MS, Ahmad T, Arnott ID, Bernstein CN, Brant $\mathrm{SR}$, Caprilli R, et al. Toward an integrated clinical, molecular and serological classification of inflammatory bowel disease: report of a Working Party of the 2005 Montreal World Congress of Gastroenterology. Can J Gastroenterol 2005;Suppl A:5A-36A. doi:10.1155/2005/269076.

53. Muise AM, Snapper SB, Kugathasan S. The age of gene discovery in very early onset inflammatory bowel disease. Gastroenterology 2012;143:285-8. doi: 10.1053/j. gastro.2012.06.025.

54. Lev-Tzion R, Turner D. Is pediatric IBD treatment different than in adults? Minerva Gastroenterol Dietol 2012;58:137-50. 
55. Pigneur B, Viola S, Viala J, Beaugerie L, Girardet JP, Ruemmele FM, et al. Natural history of Crohn's disease: comparison between childhood- and adult-onset disease. Inflamm Bowel Dis 2010;16:953-61. doi: 10.1002/ ibd.21152.

56. Molodecky NA, Soon IS, Rabi DM, Ghali WA, Ferris M, Chernoff $\mathrm{G}$, et al.Increasing incidence and prevalence of the inflammatory bowel diseases with time, based on systematic review. Gastroenterology 2012;142:46-54. doi: 10.1053/j.gastro.2011.11.016.

57. Cosgrove M, Al-Atia RF, Jenkins HR. The epidemiology of paediatric inflammatory bowel disease. Arch Dis Child 1996;74:460-1. doi:10.1136/adc.74.5.460.

58. Dinwiddie DL, Bracken JM, Bass JA, Christenson K, Soden SE, Saunders CJ, et al. Molecular diagnosis of infantile onset inflammatory bowel disease by exome sequencing. Genomics 2013;102:442-7. doi:10.1016/j. ygeno.2013.08.008.

59. Abraham $\mathrm{C}$, Cho JH. Inflammatory bowel disease. $N$ Engl $J$ Med 2009;361:2066-78. doi: 10.1056/NEJMra0804647.

60. Khor B, Gardet A, Xavier RJ. Genetics and pathogenesis of inflammatory bowel disease. Nature 2011;474: 307-17. doi:10.1038/nature10209.

61. Bousvaros A, Sylvester F, Kugathasan S, Szigethy E, Fiocchi C, Colletti R, et al. Challenges in pediatric inflammatory bowel disease. Inflamm Bowel Dis 2006;12:885913. doi: 10.1097/01.mib.0000228358.25364.8b.

62. Mamula P, Markowitz JE, Baldassano RN. Inflammatory bowel disease in early childhood and adolescence: special considerations. Gastroenterol Clin North Am 2003;32:967-995. doi:10.1016/S0889-8553(03)00046-3.

63. Seidman E, LeLeiko N, Ament M, Berman W, Caplan D, Evans $\mathrm{J}$, et al. Nutritional issues in pediatric inflammatory bowel disease. J Pediatr Gastroenterol Nutr 1991; 12:424-38.

64. Kim SC, Ferry GD. Inflammatory bowel diseases in pediatric and adolescent patients: clinical, therapeutic, and psychosocial considerations. Gastroenterology 2004;126:1550-60. doi: 10.1053/j.gastro.2004.03.022.

65. Levine A, Koletzko S, Turner D, Escher JC, Cucchiara S, de Ridder L,et al. ESPGHAN Revised Porto Criteria for the Diagnosis of Inflammatory Bowel Disease in Children and Adolescents. JPGN 2014;58: 795-806. doi: 10.1097/ MPG.0000000000000239.

66. Heyman MB, Kirschner BS, Gold BD, Ferry G, Baldassano R, Cohen SA, et al. Children with early-onset inflammatory bowel disease (IBD): analysis of a pediatric IBD consortium registry. $J$ Pediatr 2005;146:35-40. doi:10.1016/j.jpeds.2004.08.043.

67. de Bie CI, Buderus S, Sandhu BK, de Ridder L, Paerregaard A, Veres G,et al. Diagnostic workup of paediatric patients with inflammatory bowel disease in Europe: results of a 5-year audit of the EUROKIDS registry. $J \mathrm{Pe}-$ diatr Gastroenterol Nutr 2012;54:374-380. doi: 10.1097/ MPG.0b013e318231d984.
68. Prenzel F, Uhlig HH. Frequency of indeterminate colitis in children and adults with IBD - a metaanalysis. J Crohns Colitis 2009;3:277-81. doi: 10.1016/j. crohns.2009.07.001

69. Paul T, Birnbaum A, Pal DK, Pittman N, Ceballos C, LeLeiko NS,et al. Distinct phenotype of early childhood inflammatory bowel disease. J Clin Gastroenterol 2006;40:583-6.

70. Dupuis-Girod S, Medioni J, Haddad E, Quartier P, Cavazzana-Calvo M, Le Deist F, et al. Autoimmunity in WiskottAldrich syndrome: risk factors, clinical features, and outcome in a single-center cohort of 55 patients. Pediatrics 2003;111:e622-7.

71. Folwaczny C, Ruelfs C, Walther J, König A, Emmerich B. Ulcerative colitis in a patient with Wiskott-Aldrich syndrome. Endoscopy 2002;34:840-1. doi: 10.1055/s-2002-34272.

72. Pareek CS, Smoczynski R, Tretyn A.Sequencing technologies and genome sequencing. J Appl Genet 2011;52:41335. doi: 10.1007/s13353-011-0057-x. 